\title{
Molecular Characterizations of a Novel Putative DNA- Binding Protein LvDBP23 in Marine Shrimp L. vannamei Tissues and Molting Stages
}

\author{
Yanisa Laoong-u-thai ${ }^{1,2}$, Baoping Zhao ${ }^{1}$, Amornrat Phongdara ${ }^{3 *}$, Jinzeng Yang ${ }^{1,4 *}$ \\ 1 Department of Human Nutrition, Food and Animal Sciences, University of Hawaii at Manoa, Honolulu, Hawaii, United States of America, 2 Department of Chemical \\ Engineering, Faculty of Engineering, Burapha University, Chonburi, Thailand, 3 Center for Genomics and Bioinformatics Research, Prince of Songkla University, Songkhla, \\ Thailand, 4 College of Animal Science and Technology, Huazhong Agricultural University, Wuhan, People's Republic of China
}

\begin{abstract}
Background: Litopenaeus Vannamei, well known as pacific white shrimp, is the most popular shrimp in the world shrimp market. Identification and characterization of shrimp muscle regulatory genes are not only important for shrimp genetic improvement, but also facilitate comparative genomic tools for understanding of muscle development and regeneration.

Methodology/Principal Findings: A novel mRNA encoding for a putative DNA-binding protein LvDBP23 was identified from Litopenaeus vannamei abdominal muscle cDNA library. The LvDBP23 cDNA contains 639 nucleotides of protein-coding sequence with deduced 212 amino acids of predicted molecular mass $23.32 \mathrm{kDa}$ with glycine-rich domain at amino acid position 94-130. The mRNA sequence is successfully used for producing LvDBP23 recombinant protein in sf9 insect cell expression system. The expression of $\angle v D B P 23$ mRNA is presented in abdominal muscle and swimming leg muscle, as well as other tissues including intestine, lymphoid and gill. The mRNA expression has the highest level in abdominal muscle in all tested tissues. LVDBP23 transcript during the molt cycle is highly expressed in the intermolt stage. In vitro nucleic acidbinding assays reveal that LVDBP23 protein can bind to both ssDNA and dsDNA, indicating its possible role of regulation of gene transcription.
\end{abstract}

Conclusions/Significance: We are the first to report a DNA-binding protein identified from the abdominal muscle tissue of marine shrimp L. Vannamei. Its high-level specific expression during the intermot stage suggests its role in the regulation of muscle buildup during the growth phase of shrimp molt cycle.

Citation: Laoong-u-thai Y, Zhao B, Phongdara A, Yang J (2011) Molecular Characterizations of a Novel Putative DNA-Binding Protein LvDBP23 in Marine Shrimp L. vannamei Tissues and Molting Stages. PLoS ONE 6(5): e19959. doi:10.1371/journal.pone.0019959

Editor: Vladimir N. Uversky, University of South Florida, United States of America

Received January 25, 2011; Accepted April 7, 2011; Published May 20, 2011

Copyright: (@) 2011 Laoong-u-thai et al. This is an open-access article distributed under the terms of the Creative Commons Attribution License, which permits unrestricted use, distribution, and reproduction in any medium, provided the original author and source are credited.

Funding: The USDA-CSREES-TSTAR programs (Award \# 2008-34135-19343), National Research Council of Thailand, The National Research University Project of Thailand and Office of the Higher Education Commission (Grant \# SCI540527M). The funders had no role in study design, data collection and analysis, decision to publish, or preparation of the manuscript.

Competing Interests: The authors have declared that no competing interests exist.

* E-mail: Jinzeng@hawaii.edu (JY); pamornra@yahoo.com (AP)

\section{Introduction}

Litopenaeus Vannamei, well known as pacific white shrimp, is the most popular shrimp in the world shrimp market [1]. Although the breeding programs for development of high-quality bloodstock have been widely carried out in several countries many shrimp researchers point out that the lack of genetic tools and understanding of molecular mechanisms of growth is still a hurdle for effective improvement of growth traits. A better understanding of muscle growth can have significant impacts on overall shrimp growth performances. Skeletal muscle is a remarkably plastic tissue. It can undergo dramatic changes in size and contractile properties during development, as well as when responding to a variety of physiological conditions. Differentiation of skeletal muscles begins when the mesodermal cells in the early embryo become attached to the myogenic lineage, which is then followed by the differentiation of fibers to specific types [2]. In mammals, this involves the expressions of skeletal muscle-specific transcription factors such as MyoD, MFY5, Myogenin, MRF4 and MEF2, which regulate the expressions of muscle-specific genes by interactions with the regulatory DNA sequences of targeted genes $[2,3]$. After birth, a diverse number of factors such as hormones, active and passive stretch, use and disuse, and diseases can alter the size and fiber type composition of vertebrate skeletal muscles.

Crustacean muscle is structurally analogous to vertebrate skeletal muscles, with proteins organized in sarcomeres aligned along large penniform fibers. The main distinction of crustacean muscle is the different sarcomere length according to fiber type, with fast fibers organized in short sarcomeres and low mitochondrial density, and slow tonic fibers organized in long sarcomeres with high mitochondrial density. In crustaceans, muscle also exhibits a dynamic state of continuous atrophy and restoration to facilitate withdrawal from carapace at molting. The rate of $L$. vannamei growth rate varies with size, sex and time of year in the coastal waters. Molting frequency varies across different species, but is normally faster in early stages, slows down with age, and is strongly influenced by ecdsyteroid hormones [4]. Muscle loss during molting does not seem to occur in abdominal muscle [5]. 
Our results from SDS-PAGE analysis of abdominal muscles suggest the occurrence of muscle fiber rearrangement in both the premolt and postmolt stages [4].

The genes and molecular mechanisms of shrimp muscle growth have not received adequate scientific attentions to date. To gain a better understanding of shrimp growth and the underlying molecular mechanisms, we initiate a research project to identify muscle structural and regulatory genes by cDNA library and gene expression analysis. In a previous study, the abdominal muscle cDNA library of shrimp L.vannamei was successfully constructed [6]. Preliminary data analysis suggests that abundant and diverse transcripts are present in the cDNA library established by our laboratory. By degenerated PCR primer designing, we recently identified shrimp SUMO cDNA named LvSUMO-1 in $L$. vannamei. Expression of LvSUMO-1 mRNA suggest its role in the regulation of shrimp muscle protein degradation. In this research, we identified a novel gene encoding a putative DNAbinding protein, and further characterized its gene expression patterns in various shrimp muscle tissues and during the molt cycle.

\section{Results and Discussion}

\section{LvDBP23 cDNA and Amino Acid Sequences analysis}

By using degenerated oligonucleotide DNA probes, we have identified muscle regulatory genes from $L$. vannamei muscle cDNA library. One of the interesting genes reported here is a novel DNA binding protein named $L v D B P 23$. This sequence partially matchs one of the probe sequences, but it does not have significant similarity to the gene that was used as a probe. To obtain a fulllength mRNA sequence, we decided to carry out 5'RACE experiment. The result from 5'RACE DNA sequencing further extended 134 nucleotides at $5^{\prime}$ end from the primer sequence. The
mRNA sequence of $L v D B P 23$ consists of 838 nucleotides, including an ORF of 639 nucleotides, 3' UTR of 183 nucleotides with the stop codon (TAA) and polyadenylation signal of CATAAA sequence (Fig. 1). The mRNA sequence was submitted to NCBI GenBank (Accession number: JF742606). The deduced sequence of 212 amino acids from cDNA has a predicted molecular mass of $23.32 \mathrm{kDa}$. The BLAST result showed the similarity of LvDBP23 to glycine-rich protein of Drosophila melanogaster (Accession No. NP651999) with 44\% identity in amino acid sequences. By protein alignment analysis of different glycinerich proteins, it indicates that the glycine-rich region of LvDBP23 was presented on amino acid position 51-169 (Fig. 2.). In the motif scan bioinformatics software, the domain of Gly-rich is located in amino acid position 46-164 of LvDBP23 protein. The LvDBP23 amino acid sequence was also searched for conserved domain identifications. The Gly-rich domain is predicated to have DNAbinding function. Further online analysis indicates that DNAbinding site of LvDBP23 protein is located on the Gly-rich domain at the amino acid position 94-130. These data suggest that LvDBP23 is a putative DNA-binding protein.

\section{Production of LVDBP23 recombinant protein in SF9 insect cell line}

Compared with bacterial expression system, insect cell expression system is very useful for functional study of eukaryote protein because it can provide post-translational protein modification $[7,8]$. To test the LvDBP23 mRNA sequence for appropriate translation to a protein, we used SF9 insect cells for producing recombinant protein. $G F P$ and $L v D B P 23$ cDNA were inserted to pIEx-5 expression vector. Successful transfection of the plasmids was confirmed by observing green fluorescent signal with GFP plasmid with phase contract spectroscopy at $0,24,48,72 \mathrm{hr}$ after transfection. LvDBP23 protein was detected by western blot

1 GgCCGgGGACACTTCATGTtTGtGTCCGGTCAGACCACAAGTACCTGGCCAGAAGGAAAA

$\begin{array}{llllllllllllllll}1 & M & F & V & S & G & Q & T & T & S & T & W & P & E & G & K\end{array}$

61 TTAGGAGACGCCATGĀ̄TCCTCTGTTTGATATGCTGCGCGGCGCCTCCGTGCTGGCTCTG

$\begin{array}{lllllllllllllllllllll}16 & L & G & D & A & M & N & P & L & F & D & M & L & R & G & A & S & V & L & A & L\end{array}$

121 GTGTGCATGGTGTCCGCTGCGAAGCTGCCAGGATACAGTGCCGGAGGCGACTCTGGCTTG

$\begin{array}{lllllllllllllllllllllllllllllllllll}36 & V & C & M & V & S & A & A & K & L & P & G & Y & S & A & G & G & D & S & G & L\end{array}$

181 GGCGTTGACCTCGGCGGCGCAGGAGGCCACGGCGGCGTGGCAGGCGGGGCCGGAAGCGGC

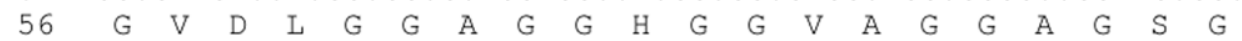

241 AATGTTTACCAGGCAGTTCTCGTCGGCAGCGGACACCTCCCTGCTAGCGCTTTTGGAGGC

$\begin{array}{llllllllllllllllllllll}76 & N & V & Y & Q & A & V & \text { L } & \text { V } & \text { G } & \text { S } & \text { G } & \text { H } & \text { L } & \text { P } & \text { A } & \text { S } & \text { A } & \text { F } & \text { G } & \text { G }\end{array}$

301 GCTGCCGGAGGCGTTGCTGGGGGCTTCGCTGGAGGCGCTGCAGGAGGTGTTGCCGGAGGC

$\begin{array}{llllllllllllllllllllll}96 & A & A & G & G & V & A & G & G & \text { F } & A & G & G & A & A & G & G & V & A & G & G\end{array}$

361 TTCGCTGGAGGCGCTGCAGGTGTTGCTGGAGGCTTCGGCGGAGGTGCTGTTGTAGATGAA

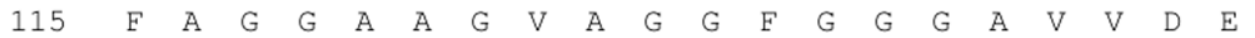

421 TACACTGGACCAGATACTGGCTCTGTCGGCCCTGTTGGACCCGTTGTCGCCGTGGAGGAC

$\begin{array}{lllllllllllllllllllllll}136 & Y & T & G & P & D & T & G & S & V & G & P & V & G & P & V & V & A & V & E & D\end{array}$

481 GAGTACGCTGGCCCAGGCCTCGACGGACCCTTCATCGCCGTCGACCCCGCCCCCCTCCCG

$\begin{array}{lllllllllllllllllllll}156 & E & Y & A & G & P & G & L & D & G & P & F & I & A & V & D & P & A & P & L & P\end{array}$

541 GAGCCCGTCGTCCCTGTCCCGACCCGCGTCACGCTTGACGACGAGTACACCGGGCCCAAC

$\begin{array}{lllllllllllllllllllll}176 & \mathrm{E} & \mathrm{P} & \mathrm{V} & \mathrm{V} & \mathrm{P} & \mathrm{V} & \mathrm{P} & \mathrm{T} & \mathrm{R} & \mathrm{V} & \mathrm{T} & \mathrm{L} & \mathrm{D} & \mathrm{D} & \mathrm{E} & \mathrm{Y} & \mathrm{T} & \mathrm{G} & \mathrm{P} & \mathrm{N}\end{array}$

601 GATGTCGCCCACGTCAGCCCCCCTGTGGGCGAGTACGGCTCTCCAAGCTTCTAAAGCTGA

$\begin{array}{llllllllllllllllllllllll}196 & D & V & A & H & V & S & P & P & V & G & E & Y & G & S & P & S & F & *\end{array}$

661 AgCTGCGGAACTGCTGTCGCTGTTGACATCTCCAATGCAAATTATCTATTTAAGATTTGT

721 AGACTGAAACGCAAATCATTTTATTTATTGCATACTCCTTAGTGAAACCTTTTGAGGAAT

781 GAATCATAATA CATAAATTATGGAAAAAAAAAAAAAAAAAAAAAAAAAAACATGTC

Figure 1. Nucleotide and deduced amino acid sequences of $\angle v D B P 23$ cDNA. Amino acids are indicated as single capital letters under each triplet codon of the nucleotide sequence. The start codon is the bold underline type and an asterisk $(*)$ indicates the stop codon. The polyadenylation signal (CATAAA) is boxed.

doi:10.1371/journal.pone.0019959.g001 
analysis at $25 \mathrm{kDa}$ (LvDBP23-His) with anti-His antibody. The result shows the recombinant protein is presented in medium and cell fraction. The recombinant proteins apparently are made of two bands (Fig. 3). The sf9 cell expression system used in the study produce secretary recombinant proteins. The cell extracts have two bands with more the large-size protein while the extracts from the medium produce two bands with more the small-size proteins. Therefore, we believe the two bands are the large-size protein with the signal peptide predominantly in cell extract, and the small-size protein without the signal peptide predominantly in the medium. The protein levels appear to increase dramatically from 0 to $72 \mathrm{hrs}$ of cell culture (Fig. 3).

\section{Expression of LvDBP23 gene in shrimp tissues}

To verify the expression of LvDBP23 transcripts and protein, we analyze the mRNA levels of LvDBP23 in various tissues from juvenile shrimp by reverse transcriptase-PCR. As shown in Fig. 4, the mRNA expressions were detected in intestine $(\mathrm{I})$, lymphoid $(\mathrm{L})$, gill (G), abdominal muscle (AM) and swimming leg muscle (SM) with the highest level in abdominal muscle. We also performed the protein expression by western blot analysis. The cytosolic and nuclear proteins were extracted and detected with LvDBP23 polyclonal antibody, which was customer-produced by Genscript. LvDBP23 protein was detected in the cytosolic fraction of the swimming leg muscle tissue (SM) at the molecular size $23 \mathrm{kDa}$ (Fig. 5). These results suggested that the LvDBP23 is not a musclespecific protein, but expressed in several other types of shrimp tissues. LvDBP23 protein was not detected in AM and other tissue samples. One possible reason may be due to the protein composition in AM samples, which may have a low percentage of the target protein (LvDBP23), but a large percentages of structural proteins such as actin, myosin etc. it may also be caused by a high degree of post-translational modifications in the tissues used in the Western blot analysis. The exact reasons of undetectable levels of LvDBP23 protein in these tissues deserve further investigations.

\section{LvDBP23 expression during molting cycle}

The $L v D B P 23$ gene was originally identified from shrimp muscle cDNA library and had the highest expression in abdominal muscle tissue. We performed RT-PCR to study LvDBP23 gene expression in shrimp abdominal muscle during different stages of molting cycle. The result showed that $L v D B P 23$ expression level was highly up-regulated in the intermolt stage (Fig. 6). Earlier reports indicate

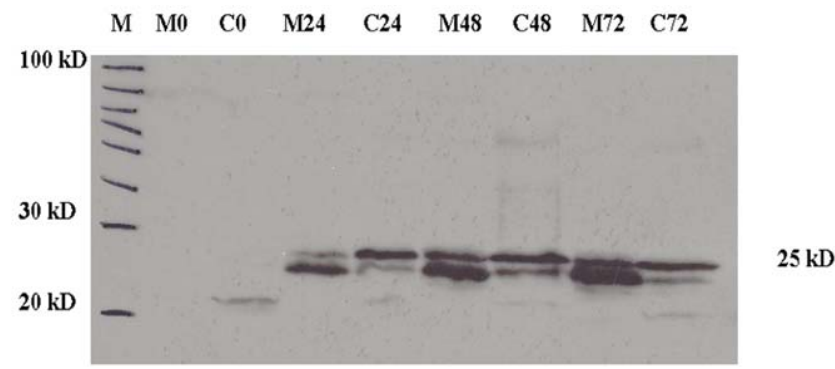

Figure 3. LvDBP23 protein expressions in Sf9 insect cell. The plasmids pIEx-5- LVDBP23-His was transfected to Sf9 insect cells. Transfected cells were incubated at $28^{\circ} \mathrm{C}$ for $0,24,48$ and $72 \mathrm{hrs}$. Expressions of LVDBP23 were detected by Western blot analysis with anti-His.tag primary antibody. Lane M0, C0, M24, C24, M48, C48, M72 and $\mathrm{C} 72$ represent the protein extracts isolated from medium (M) or cellular (C) extracts of the indicated time of cell culture.

doi:10.1371/journal.pone.0019959.g003 that there is high muscle protein synthesis during intermolt $[5,9]$. A high level of $L v D B P 23$ in the intermolt stage suggests that LvDBP23 may involve in the regulation of shrimp muscle protein synthesis.

Net muscle gain during a molt cycle is the result of protein synthesis and degradation. Although factors that control and influence both protein synthesis and degradation are critical for understanding shrimp growth, there is very limited research data available for shrimp species. The muscle morphology and biochemical changes of $L$. vannamei during molting process have been studied by Yang and his research group $[4,10]$. They found that the muscle structural $\alpha$-actin and cytoskeleton $\beta$-actin were increased during the intermolt stages, suggesting the high muscle growth during these stages. Another protein named LvSUMO-1 has been reported as the regulatory protein in shrimp myogenic differentiation and muscle formation [11]. We have not specifically identified muscle regulatory proteins well studied in vertebrate animals from this shrimp cDNA library. Several myogenic regulatory factor $(\mathrm{MRF})$ proteins expressed during myoblast cell differentiation such as MyoD, myogenin, Myf5, and MRF4 have also been well characterized in model animals [2]. The MyoD gene family has been shown to be conserved from Drosophila to vertebrates. In the invertebrates, one type of MRF family members was identified in the species $C$. elegans, sea urchin and Drosophila. The nautilus protein (NAU) was identified in Drosophila, it has a typical feature of MRF protein with a bHLH domain and has $90 \%$ similarity to the vertebrate MRF members [12]. $L v D B P 23$ is not grouped to any these muscle regulatory proteins or protein family.

\section{In vitro nucleic acid-binding assays of LVDBP23}

Different amounts of total secreted recombinant protein of GFP-His (control) and LvDBP23-His were incubated with calf thymus ssDNA-cellulose and dsDNA-cellulose beads. The result showed that only LvDBP23 protein could bind with both ssDNA and dsDNA (Fig. 7). The binding efficiency was highly dependent on the amount of protein. LvDBP23 protein showed higher interaction with ssDNA than dsDNA (Fig. 7A). In vitro nucleic acid-binding assay had been used to identify DNA/RNA binding proteins such as GR-RBP4, DdrB, ribonucleoprotein and SSB [13-16]. Based on the earlier Gly-rich domain prediction (94-130 amino acid), the results from DNA binding assays clearly suggest that LvDBP23 is a putative DNA-binding protein. According to the mRNA expression of LvDBP23 during molt cycle clearly showed the expression only in intermolt, whose stage is characterized by high muscle protein synthesis $[9,12]$. This may indicate that LvDBP23 may act as transcription factor regulating the muscle protein gene expression. Further experiments in identifying the specific DNA sequence with which LvDBP23 interacts will help classify its protein nature and function.

Several transcription factors have been reported to consist of Gly-rich amino acid region. For example, transcription factor NF$\mathrm{kB}$ is originally identified as a transcription factor that binds to the $\mathrm{kB}$ site in the intronic enhancer of the immunoglobulin k lightchain gene in B lymphocytes [17]. The Gly-rich region in NF-kB p105 functions as a processing signal for the generation of the p50 subunit [18]. In Drosophila, a DNA binding protein named MSL1 also contains a glycine-rich motif between the basic and leucinezipper-like motifs, which mediates MSL1 self-association in vitro and binding of the amino-terminal region of MSL1 to the MSL complex assembled on the male $\mathrm{X}$ chromosome. Its basic region may mediate DNA binding, and the glycine-rich region may promote the association of MSLl complexes to closely adjacent sites on the X chromosome [19]. However, glycine-rich proteins in 

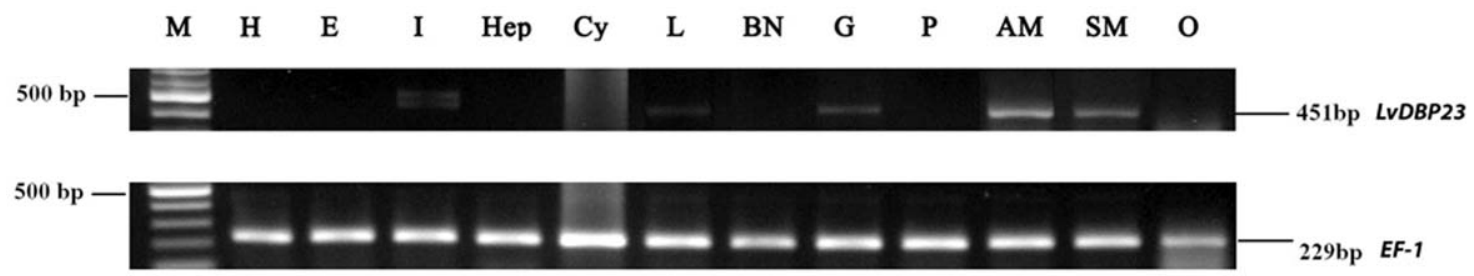

Figure 4. Tissue specificity of $\angle V D B P 23$ gene expression by RT-PCR. $L v D B P 23$ mRNA was detected in abdominal muscle (AM) and swimming leg muscle (SM) but weakly in intestine (I), lymphoid (L) and Gill (G). EF-1 gene was used as a control gene. Abbreviations in the picture represented marker $(M)$, heart $(H)$, eyestalk $(E)$, intestine $(\mathrm{I})$, hepatopancreas (Hep), haemocyte $(\mathrm{Cy})$, lymphoid $(\mathrm{L})$, brain and nerve ganglion $(\mathrm{BN})$, gill $(\mathrm{G})$, pleopods $(\mathrm{P})$, abdominal muscle (AM), swimming leg muscle (SM) and ovary (O). doi:10.1371/journal.pone.0019959.g004

plant can act as RNA binding proteins. In vitro nucleic acidbinding assays revealed the glycine-rich RNA-binding protein4 (GR-RBP4) binding sequence interacts with non-specifically to RNAs and DNAs [13]. Proteins that contain RNA-binding proteins (RBPs) and a glycine-rich region at the C-terminus (glycine-rich RNA-binding proteins, GR-RBPs) have been described in plants, and their involvement in plant stress response has been indicated by several expression analyses in maize [20].

In conclusion, we report a new shrimp mRNA named LvDBP23 identified from $L$ vannamei abdominal muscle cDNA library. The 838 nucleotides of $L v D B P 23$ cDNA contain a protein-coding sequence of 639 nucleotides and 183 nucleotides of $3^{\prime}$ non-coding region with the stop codon (TAA) and polyadenylation signal (CATAAA). This LvDBP23 mRNA was highly expressed in abdominal muscle of the juvenile shrimp, along with other tissues such as swimming legs, intestine, lymphoid and gill. The mRNA sequence of LvDBP23 was successfully used for recombinant protein production in insect cell culture. $L v D B P 23$ mRNA has a high level of expression during the intermot stage. Nuclei acidbinding assay showed LvDBP23 has both ssDNA and dsDNA binding properties, which support the predicted function of the DNA binding Gly-rich domain (amino acid 94-130). Therefore, we concluded that LvDBP23 is a novel putative DNA-bind protein, which may involve in regulation of muscle protein gene expression during the intermolt stage.

\section{Materials and Methods}

Animals and tissue sampling

Cultured, specific pathogens free (SPF) nauplius, postlarvae and 3-months-old Litopenaeus vannamei from a local shrimp farm in Kahuku HI were transported alive in plastic bags with $1 / 3$ water and 2/3 compressed air to the laboratory. Fresh tissues were collected for RNA and protein extraction following the procedure outlined by Laoong-u-thai et al. [11]. The tissue samples used for molting stage studies were the same lot as in previous reports $[10,11]$.

\section{cDNA identification and sequence analysis}

Previously, we have described the $L$. vannamei muscle cDNA library [6]. Positive muscle cDNA clones were identified by using phage lift hybridization method as described by [11]). To further identify regulatory genes for muscle growth. We believe that TGF$\beta$ proteins and muscle transcription factor play critical roles in control muscle formation and growth. Therefore, six degenerated oligonucleotide DNA probes designed by using the conserved sequences of TGF- $\beta$ and muscle transcription factor (myostatin, myostatin-like genes, MyoD and myogenin) of vertebrate and invertebrate species, including $H$. sapiens, $P$. troglodytes, $C$. familiaris, M. musculus, R. norvegicus, G. gallus, D. melanogaster, A. gambiae and A. irradians. These oligonucleotide DNA probes were labeled with biotin (IDT, Coralville, IA). Hybridization was carried out as described [11]. After hybridization, the filters were washed in $2 \times$ $\mathrm{SSC}, 0.1 \%$ SDS two times for $15 \mathrm{~min}$ at room temperature and once for $15 \mathrm{~min}$ at $50^{\circ} \mathrm{C}$ of $0.1 \times \mathrm{SSC}, 0.1 \% \mathrm{SDS}$. Blots were autoradiographed for empirically optimized exposure times by using CDP-Star ${ }^{\circledR}$ Chemiluminescence reagent as substrate for streptavidin alkaline phosphatase conjugates. The nucleotide and protein sequence similarities searches were conducted with BLAST algorithm at the National Center for Biotechnology Information (NCBI, http://www.ncbi .nlm.nih.gov/BLAST/).

To get full-length cDNA sequences, we also did 5'RACE experiment. The extension of $5^{\prime}$ sequence was amplified by $5^{\prime}$

\section{(A) Cytosolic Fraction}

$M(k D a)$ H I Hep Cy L BN G AM SM

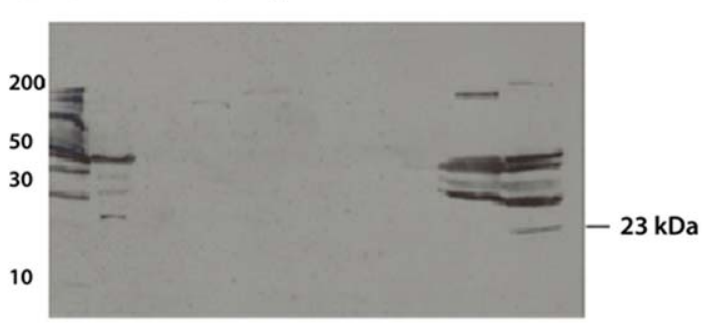

\section{(B) Nuclear Fraction}

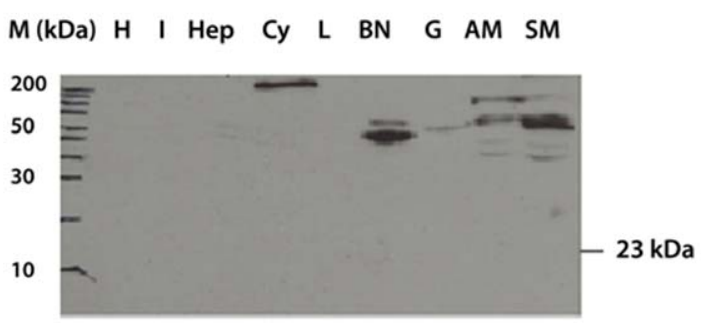

Figure 5. Tissue specificity expression of LvDBP23 protein by Western blotting. Detections of LvDBP23 protein in different tissues of cytosolic (A) and nuclear (B) fractions were shown including heart $(\mathrm{H})$, intestine (I), hepatopancreas (Hep), haemocyte (Cy), lymphoid (L), brain and nerve ganglion (BN), gill (G), abdominal muscle (AM) and swimming leg muscle (SM). Shrimp tissues were collected from 3-month juvenile shrimp. M represents the protein marker in KDa. LvDBP23 protein was detected by polyclonal primary antibody to LvDBP23 specific 15 -amino acids peptide. doi:10.1371/journal.pone.0019959.g005 


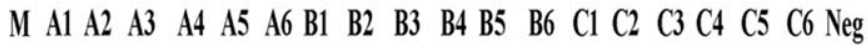

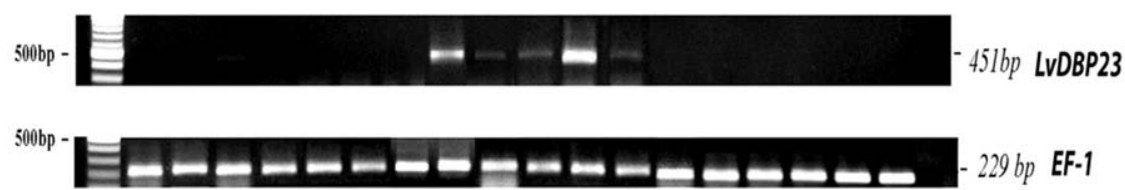

Figure 6. LVDBP23 gene expression in different molting stages by RT-PCR. Six individual shrimp of each stages of postmolt (A), intermolt (B), premolt (C) were used for LvDBP23 gene expression analysis. Reverse transcription PCR of LvDBP23 partial mRNA sequence (451 bp) was carried out with mRNA isolated from shrimp abdominal muscle. EF-1 gene was used as a control gene.

doi:10.1371/journal.pone.0019959.g006

RACE GeneRacer system (Invitrogen) with shrimp muscle mRNA template and LvDBP23 specific primer (GSP: 5' CGGCTTCGGGCGCGGC CTGCGACGC 3') and nested specific primer (Nested GSP: 5'CTGTATCGTGGC AGCTTCGCAGCGG 3'). Abdominal muscle mRNA was dephosphorylated by calf intestinal phosphatase (CIP) to eliminate truncated mRNA and other RNA. Dephospholylated mRNA was treated with tobacco acid pyrophosphatase (TAP) to remove $5^{\prime}$ cap structure from full-length mRNA. Treated mRNA was ligated with GeneRacer ${ }^{\mathrm{TM}}$ RNA oligo to 5' end of mRNA using T4 RNA ligase. A cDNA template was generated by reverse transcription using SuperScript ${ }^{\circledR}$ III and random primers. Firstly, the $5^{\prime}$ end cDNA sequence was amplified

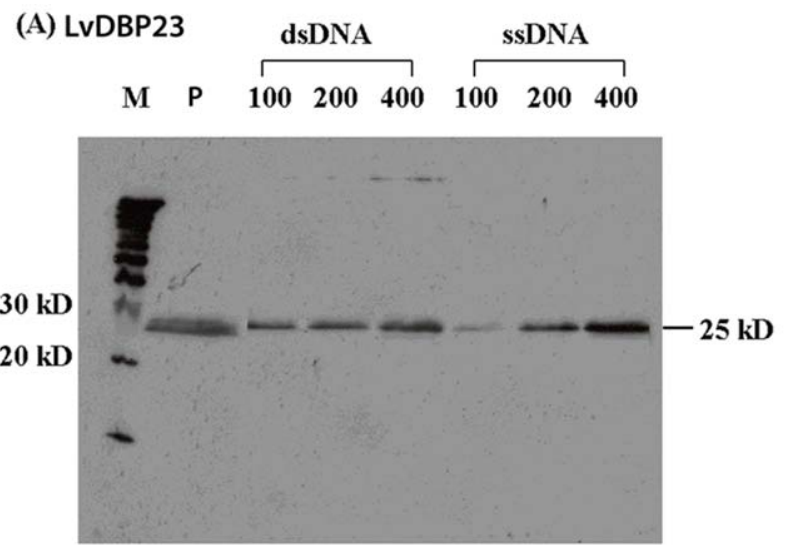

(B) GFP
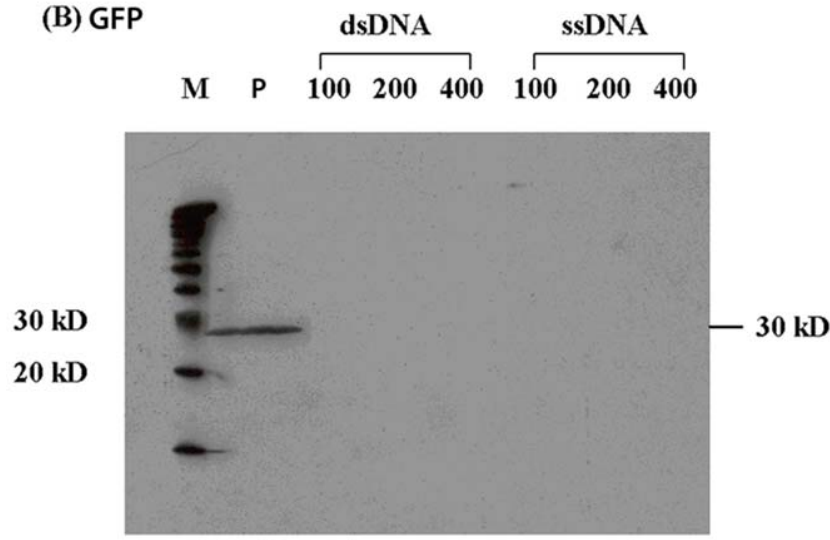

Figure 7. DNA binding protein assay. $\operatorname{LvDBP} 23$ (A) and GFP (B) proteins binding with dsDNA cellulose and ssDNA cellulose bead in different total protein amount of $100,200,400 \mu \mathrm{g}$. P: only recombinant protein without DNA in the reaction. Both proteins were detected by anti-His antibody.

doi:10.1371/journal.pone.0019959.g007 with the appropriate GeneRacer ${ }^{\mathrm{TM}} 5^{\prime}$ Primer and a gene-specific primer. Nested PCR was performed by using GeneRacer ${ }^{\text {TM }} 5^{\prime}$ nested Primer and a nested gene-specific primer.

ORF finder (NCBI) program was used for prediction of start codon position. The deduced amino acid sequence was analyzed with the NCBI Protein Sequence Analysis software. Predictions of protein function were initially analyzed by online software named Motif Scan (http://hits.isb-sib.ch/cgi-bin/PFSCAN). Search for conserved domains were analyzed on NCBI website (http://www. ncbi.nlm.nih.gov/Struc ture/cdd/wrp sb.cgi). DP-Bind, a web server for sequence-based prediction of DNA-binding residues, was used for searching DNA binding sequences (http://lcg.rit. albany. edu/dp-bind/).

\section{Expression of LvDBP23 recombinant protein in SF9 insect cell line}

The Insect cell expression (Novegen, Gibbstown, NJ) system was used to express recombinant $L v D B P 23$ protein. Briefly, $L v D B P 23$ and GFP gene were inserted to pIEx-5 plasmid between Nco $I$ and Xho $I$ restriction site. This plasmid has the protein secretion property. The plasmids pIEx-5- LvDBP23-His and pIEx-GFP-His were transformed into bacterial strain One Shot ${ }^{\circledR}$ TOP10. Plasmids were prepared by GeneJET ${ }^{\mathrm{TM}}$ Plasmid Miniprep Kit (Fermentas, Glen Burnie, MD), and inserts were confirmed by sequencing. The plasmids were transfected into Sf9 cells. Monolayer of Sf9 cells was grown in T-75 flasks at $28^{\circ} \mathrm{C}$ containing $9 \mathrm{ml}$ of BacVector Insect cell medium supplement with $5 \%(\mathrm{v} / \mathrm{v})$ fetal bovine serum by typical seeding density $1.0 \times 10^{6}$ cell. Cell density was determined by hemacytometer counts and cell viability was evaluated by Trypan Blue exclusion dye at $0.4 \%(\mathrm{w} / \mathrm{v})$ in $0.85 \%$ phosphate buffer saline (PBS). In T-75 flask, monolayers adherent Sf9 cells diluted with $10 \mathrm{ml}$ serum free BacVector Insect cell medium with cell density $4 \times 10^{5} \mathrm{cell} / \mathrm{ml}$ were transfected with $8 \mu \mathrm{g}$ pIEx5-LvDBP23 and pIEx5-GFP which were diluted with $400 \mu \mathrm{l}$ serum free BacVector Insect cell medium, using $40 \mu$ l GeneJuice Transfection Reagent (Novegen, Gibbstown, NJ), according to the manufacturer's protocol. Transfectants were incubated at $28^{\circ} \mathrm{C}$ for $48 \mathrm{hrs}$. Transfected cells were lysed by $50 \mu \mathrm{l}$ Insect PopCulture ${ }^{\circledR}$ Reagent per $1 \mathrm{ml}$ culture volume, followed by $10 \mathrm{U}$ Benzonase ${ }^{\circledR}$ nuclease per $1 \mathrm{ml}$ of the original culture volume [21]. The mixture was gently inverted several times and incubates $15 \mathrm{~min}$ at room temperature. Expression of LvDBP23-His was monitored by SDS-PAGE and western blot analysis with anti-His.tag primary antibody.

\section{RNA extraction}

Fresh different tissues of juvenile shrimp $L$. vannamei including heart $(\mathrm{H})$, eyestalk (E), intestine (I), hepatopancreas (Hep), haemocyte $(\mathrm{Cy})$, lymphoid (L), brain and nerve ganglion (BN), gill $(\mathrm{G})$, pleopods $(\mathrm{P})$, abdominal muscle (AM), swimming leg muscle $(\mathrm{SM})$ and ovary $(\mathrm{O})$ and muscle tissues of different 
developmental stages including nauplius, postlarva and juvenile were collected for RNA extraction. Total RNA was isolated by TRIZOL Reagent (Invitrogen, Carlsbad, CA), following the method described of previous work [22]. Total RNA concentrations were determined by a spectrophotometer [23].

\section{Protein extraction}

Cytoplasmic and nuclear protein were extracted as previously described [11]. Briefly, $150 \mathrm{mg}$ tissue was homogenized in buffer A (10 mM HEPES, pH 7.9, $10 \mathrm{mM} \mathrm{KCl,} 0.1 \mathrm{mM}$ EDTA) contained protease inhibitor (1 mM DTT, $0.5 \mathrm{mM}$ PMSF, $10 \mu \mathrm{g} / \mu \mathrm{l}$ leupeptin) and $40 \mu \mathrm{l}$ of $10 \% \mathrm{NP} 40$, incubated at room temperature. Cell debases and un-break cell was separated by centrifugation follow by another centrifugation for nuclear and cytosolic protein separation. Nuclear pellet was resuspened by buffer B (20 mM HEPES, pH 7.9, $0.4 \mathrm{M} \mathrm{NaCl,} 1$ mM EDTA, $10 \%$ glycerol) as the nuclear protein fraction. Protein concentration was determined by using BCA method (Pierce).

\section{Expression of LvDBP23 in different tissues}

Total RNA samples were treated with DNaseI to degrade any possible genomic DNA. Briefly, total RNA $(1.5 \mu \mathrm{g})$ was added in a $10 \mu \mathrm{l}$ reaction containing $1 \mu \mathrm{l} 10 \times$ buffer $(200 \mathrm{mM}$ Tris-HCl, $\mathrm{pH}$ 8.4, $20 \mathrm{mM} \mathrm{MgCl} 2,500 \mathrm{mM} \mathrm{KCl}), 1.5 \mu \mathrm{l}$ DNase I (1.5 U, Invitrogen, Carlsbad, CA) at $37^{\circ} \mathrm{C}$ for $15 \mathrm{~min}$, followed by inactivation with $25 \mathrm{mM}$ EDTA at $65^{\circ} \mathrm{C}$ for $10 \mathrm{~min}$. Reverse transcription (RT) was performed using $1.5 \mu \mathrm{g}$ RNA, $0.5 \mu \mathrm{g}$ Oligo (dT) 18 mers, $1.0 \mathrm{mM}$ dNTP, $4 \mu \mathrm{l}$ of $5 \times$ reaction buffer and $40 \mathrm{U}$ of M-MuLV reverse transcriptase (Fermentas, Burlington, Canada) at $37^{\circ} \mathrm{C}$ for $60 \mathrm{~min}$. The reaction was stopped by heating at $70^{\circ} \mathrm{C}$ for $10 \mathrm{~min}$. For PGR amplification, two oligonucleotide primers, B47_F2: 5' GCGACTGTGGCTTGGGCGTTGAC 3' and B47_R2: 5'CTGACGTGGGGGACATCGTTG GG 3' were designed based on the nucleotide sequence corresponding to the nucleotide positions the position 168-190 (B47_F2) and 609-635 (B47_R2) of L. vannamei LvDBP23 cDNA, respectively.

A set of control, one pair of elongation factor $1 \alpha(E F-1 \alpha)$ primer, EF-1_F and EF-1_R [24] was used during the RT-PCR amplification. PCR reactions were conducted for 40 cycles with denature at $94^{\circ} \mathrm{C}$ for $30 \mathrm{sec}$, annealing at $60^{\circ} \mathrm{C}$ for $30 \mathrm{sec}$, and extension at $72^{\circ} \mathrm{C}$ for $30 \mathrm{sec}$ in a reaction buffer consisting of $10 \mathrm{mM}$ Tris (pH 8.3), $50 \mathrm{mM} \mathrm{KCl,} 200 \mathrm{M}$ dNTPs, $0.2 \mu \mathrm{M}$ of each primer, and 2.5 U of Taq Polymerase (Biolabs Inc., Ipswich, MA) in a total volume of $50 \mu \mathrm{l}$. To visualize the amplified products, PCR reaction was electrophoresed through $1.5 \%$ agarose gel containing $0.025 \%$ ethidium bromide and observed under the UV light.

\section{References}

1. Wyban J (2009) World Shrimp Farming Revolution: Industry Impact of Domestication, Breeding and Widespread Use of Specific pathogen-free Penaeus vannamei. Proceedings of the Special Session on Sustainable Shrimp Farming, World Aquaculture 2009: 12-21.

2. Baylies MK, Bate M, Gomez MR (1998) Myogenesis: a view from Drosophila. Cell 93: 921-927.

3. Perry RL, Rudnick MA (2000) Molecular mechanisms regulating myogenic determination and differentiation. Front Biosci 5: D-750-D767.

4. Cesar JRD, Zhao B, Malecha S, Ako H, Yang J (2006) Morphological and biochemical changes in the muscle of the marine shrimp Litopenaeus vannamei during the molt cycle. Aquaculture 261: 688-694.

5. Mykles DL, Skinner DM (1990) Atrophy of crustacean somatic muscle and the proteinases that do the job. A review. J Crustacean Biol 10: 577-594.

6. Cesar JRO, Zhao B, Yang J (2008) Analysis of expressed sequenced tags from abdominal muscle cDNA library of the pacific white shrimp Litopenaeus vannamei. Animal. pp 1-7.

7. Uy R, Wold F (1977) Posttranslational covalent modification of proteins. Science 198: 890-896.

\section{Western blot analysis}

The primary antibody were custom-produced by using the synthesized peptide of amino acid position 185-198 (CVTLDDEYTGPNDVA) of LvDBP23 protein, which was designed by online antigen software for good antigenicity and surface probability. The cytosolic and nuclear protein were subjected to electrophoresis using 15\% SDS-PAGE, following by Western blotting according to the Mini Tran-Blot electrophoretic Transfer cell system (BioRad, Hercules, CA). Proteins were transferred onto PVDF membrane (BioRad, Hercules, CA) in electro blotting buffer (25 mM Tris-HCl, $190 \mathrm{mM}$ Glycine, 20\% methanol) at a constant current of $2.5 \mathrm{~mA}$ for $2 \mathrm{~h}$. The membrane was immersed in blocking buffer $(5 \%$ nonfat dry milk, $1 \times$ Tris buffer saline (TBS), pH 7.4, 0.1\% Tween 20) at room temperature for $1 \mathrm{hr}$ followed by incubation with primary antibody (rabbit polyclonal antibody, GenScript) in antibody dilution buffer ( $1 \%$ nonfat dry milk, $1 \times$ Tris buffer saline (TBS), pH 7.4, 0.1\% Tween 20) at a concentration of $1: 500$ at $4 \mathrm{C}$ overnight. Subsequently, the membrane was incubated in HRP-conjugated anti-rabbit IgG (Santa Cruz) for $2 \mathrm{~h}$ at a concentration of 1:1000, washed five time for $5 \mathrm{~min} 2$ time, $10 \mathrm{~min} 2$ time and $20 \mathrm{~min} 1$ time with $0.1 \%$ tween-20, $1 \times$ TBS and developed with Visualizer EC western blot detection kit (Millipore/Upstate, Temecula, CA).

\section{In vitro DNA binding assay}

The total secreted recombinant proteins $(100,200$ and $400 \mu \mathrm{g})$ of LvDBP23-His and GFP-His were incubated with $5 \mu \mathrm{l}$ of ssDNA-cellulose and dsDNA-cellulose beads (USB) at a concentration of $10 \mathrm{mg} / \mathrm{ml}$ in $20 \mu \mathrm{l}$ of binding buffer $(10 \mathrm{mM}$ TRIS$\mathrm{HCl}, \mathrm{pH}$ 7.4, $2.5 \mathrm{mM} \mathrm{MgCl} 2,0.5 \%$ Triton X-100, and $125 \mathrm{mM}$ $\mathrm{NaCl}$ and $10 \%$ Glycerol) with $1 \mu \mathrm{l}$ each of $10 \mathrm{mg} / \mathrm{ml}$ Leupeptin and $1 \mathrm{mM}$ Dithiothreitol (DTT). The mixture was incubated on ice at $4^{\circ} \mathrm{C}$ for overnight with shaking, and the beads were washed three times to remove the unbound-proteins with the $100 \mu \mathrm{l}$ of binding buffer (without Leupeptin and DTT). After the last wash, the samples were re-suspended with $10 \mu \mathrm{l}$ of binding buffer follow by boiling in SDS loading buffer. The amount of LvDBP23-His and GFP-His protein retained on the beads was determined by western blotting with anti-His antibody.

\section{Author Contributions}

Conceived and designed the experiments: YT JY AP. Performed the experiments: YT BZ JY. Analyzed the data: YT JY. Contributed reagents/ materials/analysis tools: YT JY. Wrote the paper: YT JY.

8. Meek DW, Knippschild U (2003) Posttranslational modification of MDM2. Mol Cancer Res 1: 1017-1026.

9. El Haj AJ, Houlihan DF (1987) In Vitro and In Vivo Protein Synthesis Rates in A Crustacean Muscle During the Moult Cycle. J Exp Biol 127: 413-426.

10. Cesar JRO, Yang J (2007) Expression patterns of ubiquitin, heat shock protein 70 , alpha-actin and beta-actin over the molt cycle in the abdominal muscle of marine shrimp Litopenaeus vannamei. Molecular Reproduction and Development 74: 554-559.

11. Laoong-u-thai Y, Zhao B, Phongdara A, Ako H, Yang J (2009) Administration of a mutated myostatin propeptide to neonatal mice significantly enhances skeletal muscle growth. Molecular Reproduction and Development 77: 7682.

12. Michelson AM, Abmayr SM, Bate M, Arias AM, Maniatis T (1985) The role of calcium-dependent proteinase in molt-induced claw muscle atrophy. Prog Clin Biol Res 180: 141-150.

13. Kwak KJ, Kim YO, Kang H (2005) Characterization of transgenic Arabidopsis plants overexpressing GR-RBP4 under high salinity, dehydration, or cold stress. J Exp Biol 56: 3007-3016. 
14. Sugiman-Marangos S, Junop MS (2010) The structure of DdrB from Deinococcus: a new fold for single-stranded DNA binding proteins. Nucleic Acids Res 38: 3432-3440.

15. Zhang S, Yang H, Li L, Tan H (2009) Novel ssDNA-binding properties of SSB2 and SSB3 from Thermoanaerobacter tengcongensis. Wei Sheng Wu Xue Bao 49: $453-459$.

16. Sugita M, Sugiura M (2010) The structure of DdrB from Deinococcus: a new fold for single-stranded DNA binding proteins. Nucleic Acids Res 38: 3432-3440.

17. Sen R, Baltimore D (1986) Multiple nuclear factors interact with the immunoglobulin enhancer sequences. Cell 46: 705-716.

18. Lin L, Ghosh S (1996) A glycine-rich region in NF-kappaB p105 functions as a processing signal for the generation of the p50 subunit. Mol Cell Biol 16: 2248-2254.

19. Li F, Parry DA, Scott MJ (2005) The amino-terminal region of Drosophila MSL1 contains basic, glycine-rich, and leucine zipper-like motifs that promote $\mathrm{X}$ chromosome binding, self-association, and MSL2 binding, respectively. Mol Cell Biol 25: 8913-8924.
20. Go'mez J, Sa'nchez-Martı'nez D, Stiefel V, Rigau J, Puigdome'nech PMP (1988) A gene induced by the plant hormone abscisic acid in response to water stress encodes a glycine-rich protein. Nature 344: 262-264.

21. Li Z, Zhao B, Kim YS, Hu CY, Yang J (2009) Administration of a mutated myostatin propeptide to neonatal mice significantly enhances skeletal muscle growth. Molecular Reproduction and Development 77: 76-82.

22. Laoong-u-thai Y, Zhao B, Phongdara A, Ako H, YangJ (2009) Identifications of SUMO- 1 cDNA and its expression patterns in Pacific white shrimp Litopeanaeus vannamei. International Journal of Biological Sciences 5: 205-14.

23. Li Z, Kawasumi M, Zhao B, Moisyadi S, Yang J (2010) Transgenic Overexpression of Growth Differentiation Factor 11 Propeptide in Skeleton Results in Transformation of the Seventh Cervical Vertebra into a Thoracic Vertebra. Molecular Reproduction and Development 77: 990-997.

24. Cesar JRO, Yang J (2007) Expression patterns of ubiquitin, heat shock protein 70 , alpha-actin and beta-actin over the molt cycle in the abdominal muscle of marine shrimp Litopenaeus vannamei. Molecular Reproduction and Development 74: 554-559. 